\title{
The influence of particle-size distribution on critical state behavior of spherical and non-spherical particle assemblies
}

\author{
M.D. Jiang ${ }^{1}$, Z. X. Yang 2 , D. Barreto 3 , Y.H. Xie ${ }^{4}$
}

\begin{abstract}
This paper presents an investigation into the effects of particle-size distribution on the critical state behavior of granular materials using Discrete Element Method (DEM) simulations on both spherical and non-spherical particle assemblies. A series of triaxial test DEM simulations examine the influence of particle-size distribution (PSD) and particle shape, which were independently assessed in the analyses presented. Samples were composed of particles with varying shapes characterized by overall regularity (OR) and different PSDs. The samples were subjected to the axial compression through different loading schemes: constant volume, constant mean effective stress, and constant lateral stress. All samples were sheared to large strains to ensure that a critical state was reached. Both the macroscopic and microscopic behaviors in these tests are discussed here within the framework of the anisotropic critical state theory (ACST). It is shown that both OR and PSD may affect the response of the granular assemblies in terms of the stress-strain relations, dilatancy, and critical state behaviors. For a given PSD, both the shear strength and fabric norm decrease with an increase in $O R$. The critical state angle of shearing resistance is highly dependent on particle shape. In terms of PSD, uniformly distributed assemblies mobilize higher shear strength and experience more dilative responses than specimens with a greater variation of particle sizes. The position of the critical state line in the e-p' space is also affected by PSD. However, the effects of PSD on critical strength and evolution of fabric are negligible. These findings highlight the importance of particle shape and PSD that should be included in the development of constitutive models for granular materials.
\end{abstract}

Keywords: discrete element method, critical state, particle-size distribution, particle shape, fabric anisotropy

\section{Introduction}

Seminal work by Roscoe et al [1] led to the emergence the critical state concept. It states that soils and other granular materials, when continuously sheared will reach a well-defined critical state [2]. Upon the onset of this critical state, additional shear distortion occurs without any further changes in mean effective stress, deviatoric stress, or specific volume. That is the well-known critical state theory (CST) and can be expressed mathematically [3]:

$$
\& t=0, \quad \&=0, \quad \&=0 \text { but } \quad \& \neq 0
$$

where $p$ ' is the mean normal effective stress, $\mathbf{s}$ the deviatoric stress tensor, $\varepsilon_{\mathrm{v}}$ the volumetric strain, e the deviatoric strain tensor, and a superposed dot denotes the rate. Upon reaching the critical state, the

\footnotetext{
${ }^{1}$ Postgraduate student, Department of Civil Engineering, Zhejiang University, Hangzhou 310058, Zhejiang, China, email: jiangmingdong@zju.edu.cn

2 Professor, Department of Civil Engineering, Zhejiang University, Hangzhou 310058, Zhejiang, China, email: zxyang@zju.edu.cn, corresponding author

${ }^{3}$ Lecturer, School of Engineering and the Built Environment, Edinburgh Napier University, Merchiston Campus, Edinburgh EH10 5DT, Scotland, UK, email: D.Barreto@napier.ac.uk

${ }_{4}$ Assistant Engineer, Changjiang Institute of Survey, Plan, Design, and Research, Wuhan 430010, Hubei, China; formerly, Postgraduate Student, Dept. of Civil Engineering, Zhejiang University, Hangzhou,310058, China. email: xieyihong@cjwsjy.com.cn
} 
stress ratio $\eta=q / p$ ' and the void ratio $e$ will satisfy the following conditions,

$$
\eta=\eta_{c}=\left(q / p^{\prime}\right)_{c}=M \text { and } e=e_{c}=\hat{e}\left(p^{\prime}\right)
$$

where $M$ is the critical state stress ratio and it is related to the Lode angle reflecting the shear mode, such as triaxial compression or extension, etc. The subscript 'c' denotes critical state. Though the critical state theory does not provide any specific models, it is widely used to interpret the behavior of soil and numerous constitutive models have been developed within the framework of CST; see some recent examples [4-7].

The uniqueness of critical state line in e- $p$ ' plane is one of the most controversial issues because the critical state is originally based on experimental observations rather than derived from sound theories. In most constitutive models, the critical state is a reference state and thus its uniqueness has evoked increasing debate for many years However, reaching the critical state in physical tests is challenging. Shear banding and non-uniform deformations can inevitably occur as a result of boundary conditions during testing. Furthermore, a sufficiently large shear strain is required prior to the arrival of critical state, especially under triaxial extension conditions. Recently, Li and Dafalias [3] revisited this subject from the perspective of thermodynamical principles and proved that the two conditions of the classic CST set out in Eq. (2) are not sufficient for the attainment of the critical state. Hence, they proposed an additional condition for the microstructure (i.e. fabric) of soils at critical state. According to the anisotropic critical state theory (ACST) that they developed, a deviatoric fabric tensor $\mathbf{F}$ that characterizes the microstructure of soils will also evolve towards the critical state, i.e. the norm $F$ reaches a critical value $\left(F_{\mathrm{c}}\right)$ and the direction $\mathbf{n}_{F}$ evolves toward the loading direction $(\mathbf{n})$. Within the ASCT framework, the uniqueness of CSL in e-p' plane is therefore ensured. Zhao and Guo [8] performed DEM simulations to verify ACST's conditions. Spherical particles were employed in their simulations using different shear modes (i.e. Lode angles). A unique critical state line was observed in the numerical analysis, and the fabric also reached a constant value at the critical state. Noting that only isotropic samples were considered in [8], anisotropic samples composed of clumped particles with varying initial anisotropic intensities were used by Yang and $\mathrm{Wu}$ [9]. Their numerical results have shown that a unique CSL exists in e- $p$ ' plane, irrespective of the initial fabrics and shear mode (note that only triaxial compression and extension were considered). A unique critical state fabric norm which is independent of both initial density and mean normal stress (as advocated by ACST) is also obtained provided that normalized measure of fabric was adopted (e.g. by specific volume) [10]. Recently, Xie et al. [11] extended the numerical simulations in Yang and $\mathrm{Wu}$ [9] to examine the critical state responses of granular materials composed of varying shapes of particles under generalized stress conditions beyond the triaxial plane. Their results indicated that the position of the critical state line is only slightly affected by the particle shape for a given 'equivalent' PSD, although the critical state angle of shearing resistance was significantly affected. In the full variation of Lode angles between 0 and $60^{\circ}$, the critical fabric norm $F_{\mathrm{c}}$ trajectory in the $\pi$-plane depends on the particle shape, and the shape of the trajectory is found to be approximately reciprocal to the critical state yield surface. This is in agreement with the theoretical prediction by Li and Dafalias [10] and observations in other existing DEM studies (e.g. [12]).

It is well known that both the particle shape and particle-size distribution (PSD) influence the mechanical responses of granular materials. Existing experimental results concerning the effects of both the particle shape and PSD on the critical state responses can be summarized as follows. Firstly, the critical state shearing resistance of granular soils can be significantly influenced by the shape of 
sand [13-15]. In addition, through triaxial tests on sand and mixtures of sand and glass beads, Yang and Luo [16] showed that the CSL line in both $p^{\prime}-q$ and $e-p$ ' plane was sensitive to the shape of glass beads (spherical or angular) in the mixture. Consequently, correlations between particle shape parameters (aspect ratio, sphericity and convexity) and critical state line parameters (gradient and intercept) were proposed. Although the samples for both the natural sand and mixtures were controlled to have the same PSD, their results are slightly different from those in Xie et al. [11], in which the particle shape, represented only by aspect ratio, has negligible effect on CSL in e-p' plane. Second, the effect of the PSD on the critical state is yet inconclusive based on the existing studies in literature. Some studies indicated that the critical state friction angle was related to PSD [17,18], while others $[19,20]$ found that varying PSD had little influence on the critical state friction angle. Although it is widely accepted that PSD does have influence on the CSL location in e-p' plane [21-26], how the position of CSL in e-p plane is influenced remains unclear.

DEM developed by Cundall and Strack [27] has been proved to be a promising tool to investigate the fundamental behavior of granular materials under various loading paths [8,9,28-31]. Particle shape effects have been extensively investigated using DEM because the varying shapes of particles can be conveniently considered in virtual samples as compared with those in laboratory. Nouguier-Lehon et al. [32] performed 2D numerical simulations considering different particle shapes and found that the angle of shearing resistance increased with particle elongation. Using Voronoi tessellation, a polygonal packing was generated with initially zero void ratio [33]. Their studies showed that the angularity of the particles significantly affected the force distribution and its mechanical behavior. In order to include the effect of diversity of particle shapes in real soils, randomly generated convex polygons were generated, while the overall behavior was similar to the observations from both experiments and numerical simulations with circular particles [34]. In three-dimensional simulations, $\mathrm{Ng}[35,36]$ adopted ellipsoids to investigate the effects of particle shape on both the macroscopic response of granular assembly and the evolution of microstructure. Using clumped particles, Xie et al. [11] explored the effect of the aspect ratio of the particles on the behavior of the granular materials, in particular the critical state responses and the quantification of the critical state fabric. Although quantitative correlations can be obtained between the parameters of critical state line and the aspect ratio, a comprehensive investigation into the effect of particle shape represented by varying shape factors (e.g. sphericity, convexity and roundness) is desirable to obtain more persuasive conclusion. The influence of PSD on the critical state behavior of granular materials has also been investigated via DEM. Recognizing that soils may experience changes in grading, Wood and Maeda [21] examined the effect of grading changing on the critical state conditions of two dimensional particle assemblies. Yan and Dong [37] studied the effects of PSD on stress-strain-strength responses of the two dimensional assembly and found that well-graded PSDs (particles distributed in a wider range of diameters) may have a lower the position of the CSL in the e-p' space, while no significant difference in the critical stress ratio was observed due to the grading. Note above both studies only concern two dimensional circular particles, while either non-circular particles or three-dimensional analyses evaluating the effects of both PSD and particle shape have not been published.

Recently, the effect of the PSD and particle shape on the shear strength has also been investigated with Contact Dynamics (CD). Through numerical simulations, it has been found that both the mechanical behavior (e.g. shear strength) and microstructure (e.g. contact network) were strongly dependent on the degree of particles' angularity [38], elongation [39], and platyness [40]. However, the size span and shape of PSD had no effect on the shear strength for both frictional and frictionless 
particles according to their 2D simulations [41-44]. Note that these CD studies focused merely on the critical state shear resistance and no discussion on the CSL in the e-p' space and the related microscopic responses were provided.

Particle crushing or breakage is a common observation in practical engineering in which the high stress level is involved, such as pile driving and large earth-fill dams. When breakage takes place, the grading would also experience changes. Through experimental tests on crushable carbonate sand, Miao and Airey [45] found that both the particle shape and grading evolved during the shearing while no unique steady state grading of the sand can be obtained. Through triaxial tests, Bandini and Coop [24] and $\mathrm{Yu}$ [46] found that particle breakage may lead to a downward translation and anti-clock rotation of critical state line in $e-\log \left(p^{\prime}\right)$ space while maintaining a constant critical state angle of shearing resistance. However, the tests reported by Xiao et al [26] indicated that particle breakage may generate multiple CSLs. They were however parallel with a constant slope in the e-log $\left(p^{\prime}\right)$ space. The consequence of particle breakage can be essentially seen as a combination of concurrent variations in both particle shape and PSD. The inconsistent position change mode, translation only or both translation and rotation (of the CSL), outlined above may be caused by coupling effects between particle shape and PSD. It is not easy to isolate these two factors in an independent manner in physical experiments.

In summary, the role that the PSD and particle shape plays in affecting the critical state behavior of sand has not yet been fully understood. DEM is a promising tool as it enables tracking of the microscale quantities. Using DEM samples can be generated with controllable particulate features, such that the influences of the particle shape and PSD can be independently examined. The main purpose of this paper is to investigate the effects of both the particle shape and PSD on the mechanical behavior of granular soils. Observations of micro- and macro-scales at the critical state are of particular interest. A series of DEM triaxial simulations on samples with varying particle shape and grading can be performed using three-dimensional DEM. Numerical observations are discussed within the context of the ACST.

\section{Simulation procedures}

\section{Particle shape and particle-size distribution (PSD)}

In general, particle shape can be characterized by the following four major parameters: aspect ratio $(A R)$, convexity $(C)$, sphericity $(S)$, and roundness $(R)$, although several other parameters are also frequently used, such as elongation, roughness, angularity, etc. (e.g. $[32,47,48])$. The clumped particle method consisting of two overlapped spheres is used as the basic element in generating numerical samples for this study (see Fig. 1). The equivalent particle diameter is defined as the diameter of the spherical particle with the same volume as the clumped particle. Noting that the influence of aspect ratio with varying $A R$ values has been investigated by Xie et al. [11], particles with $A R=1$ and 0.714 are employed in this study. Fig. 2 illustrates the definitions of these four major parameters that characterizing the particle shape in two dimensions. $A R$ is the ratio of the minor axis length to the major axis length. $S$ refers to the ratio of the perimeter of the area-equivalent circle to its actual perimeter. $C$ is defined as the ratio of the particle area to the area of the single particle if all concavities are filled. $R$ describes the surface irregularities of a particle and is calculated by the average radius of 
curvature of surface features divided by the maximum radius of the inscribed sphere [49]. These 2D shape describers can be easily extended to quantify three-dimensional measurements. For the particles adopted in this study, roundness $R$ is always equal to unity because each clumped particle is made up by two overlapped identical spheres, and the aspect ratio is the main particle shape variable. As overlapping extent is quantified by the $A R$ in clumped particle, the variation in $A R$ will affect inevitably other shape variables. Therefore, a synthetic shape parameter, termed overall regularity (OR) is employed to quantify the particle shape in a consistent manner. For simplicity, $O R$ is calculated by an average of these four shape variables, $A R, S, C$ and $R$. Note that $O R$ was first proposed by Yang and Luo $[16,19]$ but herein the new shape factor $R$ is added for completeness, although it is fixed as unity in the present study. Table 1 lists the four shape parameters and the synthetic shape parameter for the clumped particles used in the simulations. For comparison, all the shape parameters for individual spheres are equal to 1 .

With reference to Fig. 3, the properties of the particle-size distributions (PSD) can be characterized by several parameters, such as mean particle size $\left(D_{50}\right)$, coefficient of uniformity $\left(C_{\mathrm{u}}\right)$, and coefficient of curvature $\left(C_{\mathrm{c}}\right)$, amongst others. In this study, $D_{50}$ is fixed as $0.26 \mathrm{~mm}$ for all the samples; $C_{\mathrm{c}}$ varies in a small range from 0.99 to 1.01 and could be considered as a constant; the only variable is $C_{\mathrm{u}}$ that ranging from 1 (PSD_1) to 2.564 (PSD_4). As $C_{\mathrm{u}}$ increases, the constituted particles of the sample have a larger range of sizes. Four PSD curves are shown in Fig. 3 and are used in this study. Table 2 lists the usual grading parameters. PSD_1 represents specimens with non-disperse particles while PSD_4 refers to a relatively well-graded PSD. The numerical scheme employed in this study by considering two particle shapes and four grading curves can isolate the effects of particle shape and PSD independently.

\section{Numerical test program and procedure}

Three-dimensional DEM numerical tests were conducted using the open source discrete-element code YADE [50]. Periodic boundaries were imposed to eliminate any boundary effects. A cubic sample is generated and regarded as the representative volume element (RVE). In this study the contact model consists of two parts: a linear stiffness model and a Coulomb-type slip model. Two parameters are required in the stiffness model, i.e. $k_{\mathrm{n}}$ (normal stiffness) and $k_{\mathrm{s}}$ (tangential stiffness). The normal and the tangential components of the contact force are proportional to the overlap between two entities in contact and to the tangential displacement at contact, respectively. The tangential component of the contact force is limited in magnitude related to with respect to the inter-particle friction $\mu$, according to the Coulomb-type slip model. Three different servo-controlling algorithms were used. A stress-controlled servo-control was used during the consolidation stage to reach the desired stress state. A strain-controlled boundary is used during constant-volume tests, which mimic the undrained tests in the laboratory [11,29,51-53]. A mixed servo-control was used for drained tests, in order to achieve different stress paths including constant mean normal stress and conventional drained (triaxial) compression tests. The parameters used in the simulations are summarized in Table 3. Note that a low unbalanced force ratio guarantees static equilibrium before shear, and the chose strain rate ensures quasi-static deformation conditions.

The following numerical technics were adopted in the simulations. For computational efficiency a density scaling approach was adopted. Thornton and Antony [29] showed that the use of particle density scaling has no effect on the results for quasi-static conditions. In this study, the material density 
was set 1000 times bigger than the original one in order to increase the time step $\Delta t_{c r}=r \sqrt{\rho / E}$, where $r$ is the particle radius, $\rho$ is the density of the particle assembly, and $E$ is Young's modulus. A small fraction of this critical time-step was then used to guarantee numerical stability. Different inter-particle friction coefficients assigned during at different stages for the simulations. During the consolidation stage, in order to obtain the samples with various initial densities, different inter-particle friction coefficients were used. Once the target stress state was reached, the friction coefficient was restored to commonly used $\mu=0.5$, followed by additional cycling to (once again) guarantee equilibrium conditions before shear. Static equilibrium during the subsequent shearing is ensured by keeping the unbalanced force ratio lower than 0.0001 as recommended by Kuhn et al [54], as discussed before.

A broad set of initial mean effective stress $(100 \mathrm{kPa}, 200 \mathrm{kPa}, 500 \mathrm{kPa}, 1,000 \mathrm{kPa}$, and $1,500 \mathrm{kPa})$ and various stress paths (conventional drained, constant volume, and drained constant $p^{\prime}$ ) were considered in the simulations of the samples with varying PSDs (two densities each). Note there is no particle breakage allowed such that the PSD does not change for each individual simulation. All samples are sheared to a large axial strain of approximately $50 \%$ where the critical state failure could be verified. A total of 240 numerical simulations were performed, including the following combinations: 2 shape parameters $(O R), 4$ PSDs, 5 initial confining pressures, 2 initial densities, and 3 types of stress paths. These tests allow for the determination of the critical state lines and the fabric evolutions with confidence.

\section{Simulation results}

\section{Typical macroscale responses}

In Figs. 4-5, the shear responses of two specimens composed of spheres $(O R=1)$ with different PSD under the initial confining pressure of $100 \mathrm{kPa}$ are presented. PSD_1 refers to the specimens with non-disperse particles while PSD_4 has the widest grading range considered in this study. These four samples were generated such that the response at similar initial void ratio $e_{0}=0.625 \pm 0.002$ could be assessed. Remarkably, the difference in PSD results in a significant effect on the stress-strain response. Fig. 4 compares the responses of samples under the constant volume stress path (undrained condition). It is seen that the sample with widest PSD liquefies, while the other samples exhibit a dilative response before the critical state is attained. Results of drained constant mean effective stress paths for the same specimens are illustrated in Fig. 5. Overall, the sample is stiffer and more dilative as $C_{\mathrm{u}}$ decreases. The well-graded sample (PSD_4) exhibits strain-hardening response accompanied by volume contraction, while the other three samples exhibit strain-softening responses accompanied by significant dilation. The peak deviatoric stress increases and more volume dilation can be observed as $C_{\mathrm{u}}$ decreases. These differences can be explained in terms of the PSD range. For well-graded specimens, smaller particles can accommodate between voids promoting compression. Alternatively, in the specimens with non-disperse particles, particle movements are constrained as particles need to climb and roll over each other during shear. Similar observations have been found in laboratory experiments [19] and DEM simulations [37]. Interestingly, the four samples reach critical state failure with nearly the same critical stress state ( $p$ ' and $q$ ) for each drained stress path but have distinct volumetric strains. This observation implies that PSD may affect the position of CSL in the $e-p$ ' plane while it has no influence on the 
critical state angle of shearing resistance. This phenomenon is discussed later in more detail.

Figs. 6-7 show the response of specimens with clumped particles $(O R=0.914)$ under initial confining pressure $p_{0}{ }^{\prime}=100 \mathrm{kPa}$ and similar initial void ratio $e_{0}=0.624 \pm 0.002$. First, it is seen that the samples with clumped particles show similar behaviors of those with spherical particles illustrated in Figs. 4-5. Under undrained conditions, samples with greater $C_{\mathrm{u}}$ are more contractive and undergo liquefaction failure, while specimens with non-disperse particles exhibit more dilative responses. As before, under drained conditions, the sample with $C_{\mathrm{u}}=2.564$ shows strain-hardening response with volume contraction, while the specimen with non-disperse particles with $C_{\mathrm{u}}=1$ shows significant dilation accompanied by slight strain-softening after the peak state.

\section{Fabric quantification and microscopic responses}

Fabric evolution refers to the microstructural features of the granular media, including the shape and spatial arrangement of the particles and associated voids and their interactions [55]. The fabric within a REV can be quantified by the fabric tensor based on the statistical analysis on the microscopic entities, such as contact unit norm, particle orientation and branch vector, etc. In this study, a deviatoric second-order fabric tensor $\mathbf{F}$ is employed to characterize the microstructures represented by the contact unit norm, which has been widely used and found to be a preferable measure in recent studies $[8,9,11]$. More detailed information on the quantification of the fabric tensor $\mathbf{F}$ can be found in $[3,11,56]$. Note that as a deviatoric tensor, $\mathbf{F}$ has two non-trivial invariants, i.e. the norm $F$ of $\mathbf{F}$ and unit direction $\mathbf{n}_{F}$, which can be written as:

$$
\mathbf{F}=F \mathbf{n}_{F} \text { with } F=\sqrt{\mathbf{F}: \mathbf{F}}, \mathbf{n}_{F}: \mathbf{n}_{F}=1, \operatorname{trn}_{F}=0
$$

The direction $\mathbf{n}_{F}$ is traceless and presents the unit-norm deviatoric tensor-valued direction, and is also related to Lode angle of the fabric $\theta_{F}\left(0^{\circ} \leq \theta_{F} \leq 60^{\circ}\right)$ by the following equation:

$$
\cos 3 \theta_{F}=\sqrt{6} \operatorname{trn}_{F}^{3}
$$

Note that the fabric tensor $\mathbf{F}$ defined by Eq. (3) from DEM may not be a per-volume measure as required by the ACST [3], therefore certain normalization of $\mathbf{F}$ is necessary to yield a thermodynamic admissible fabric measure as discussed before. According to Yang and $\mathrm{Wu}$ [9] and Xie et al. [11], normalizing $\mathbf{F}$ with the specific volume $v(=1+e)$ of the REV may lead to satisfactory results:

$$
\mathbf{F}^{\prime}=\frac{\mathbf{F}}{v}=\frac{\mathbf{F}}{1+e}
$$

Although a more accurate treatment using the plastic part of the specific volume $v^{\mathrm{p}}$ to replace the total $v$ in Eq. (5) is desired, the studies by Yang and Wu [9] and Xie et al. [11] have shown the elastic part of the void ratio is negligible and the adoption of the normalizer of $v$ yields acceptable accuracy.

The evolution of the fabric tensor during shearing was examined for all the tests conducted except the liquefied samples (because all inter-particle contacts are eventually lost) in terms of the evolution of the fabric norm $F^{\prime}$ and the fabric Lode angle $\theta_{F}$. Fig. 8 shows the effect of PSD on the fabric evolution of samples composed of spherical particles $(O R=1)$ under drained constant $p$ ' conditions with $p_{0}{ }^{\prime}=100$ $\mathrm{kPa}$. It is seen that the fabric norm $F$ ' increases with the axial strain for all the samples with different PSDs, while a slight reduction in $F$ ' for sample with PSD_1 after peak is observed. Although the fabric norm for the sample with lower $C_{\mathrm{u}}$ tends to evolve more slowly than that with greater $C_{\mathrm{u}}$, it eventually 
reaches a common value at critical state for all the samples shown in Fig. 8a. For the fabric direction, a steep reduction of fabric Lode angle can be observed at the very beginning of shearing $(<2 \sim 3 \%$ of axial strain) and $\theta_{F}$ subsequently drops to zero accompanied by slight fluctuations. This observation means that the fabric direction is co-directional with the loading direction, because the Lode angle of triaxial compression is also zero. Similar results displayed in Fig. 9 are observed for clumped particles with higher critical values of $F_{c}$ ' accompanied by a more gradual evolution.

The coordination number quantifies the average number of contacts per-particle within an assembly and can be used to quantify the micro-structural evolution. The mechanical coordination number defined by Thornton and Anthony [57] can be expressed as

$$
Z_{\mathrm{m}}=2 \frac{N_{c}-N_{p}^{1}}{N_{p}-\left(N_{p}^{1}+N_{p}^{0}\right)}
$$

where $N_{p}$ and $N_{c}$ are the numbers of particles and contacts, respectively; and $N_{p}{ }^{1}$ and $N_{p}{ }^{0}$ are the numbers of particles with only one contact and without any contacts, respectively. The rationale behind this definition is that particles with less than two contacts do not contribute to stress transmission. As shown in Fig. 10, the coordination number $Z_{\mathrm{m}}$ is found to decrease with the axial strain under drained conditions, as observed in many earlier DEM studies. For samples composed by either spherical particles or clumped particles, the higher $C_{\mathrm{u}}$, the lower $\mathrm{Z}_{\mathrm{m}}$ is. This implies that a wide PSD range increases the number of "floating" particles that do not contribute to stress transmission. Moreover, in comparison with the stress strain curves shown in Fig. 5a and Fig. 7a, the larger coordination number may explain to higher peak shearing resistance, which is also consistent with the experimental results reported by Oda [58]. The evolution of the coordination number under undrained condition is illustrated in Fig. 11. It is seen that for liquefied samples, $Z_{\mathrm{m}}$ reduces to its minimum value $(\sim 2)$, indicating that the structure collapses [59] and the sample is under unstable state $\left(Z_{\mathrm{m}}<4\right.$ [60]). For the other samples, $Z_{\mathrm{m}}$ slowly increases towards a constant value, dependent on the value of $C_{\mathrm{u}}$. This observation implicitly supports our earlier postulate in which specimens with non-disperse particles experience a more dilative volumetric response.

In summary, micro-mechanical analyses indicate that at the critical state, coordination number reaches a steady value which is related to particle shape and $C_{\mathrm{u}}$. Both the fabric norm and the direction reach the constant values, which is in good agreement with the concurrent condition required by the ACST, apart from other conditions set out in CST.

\section{Critical state analysis}

\section{Influence of particle shape and PSD on critical stress ratio}

The influence of particle shape and PSD on the critical stress ratio is of significant importance from the practical engineering perspective. They are key parameters in geotechnical analysis and design. It has been generally agreed that samples with angular particles may provide more shear resistance than those composed of rounded or sub-rounded particles $[11,15,16,32,61]$. However, the influence of PSD on the critical stress ratio is rarely investigated and the relevant results are not always convincing. This is because the influencing factors are all mixed in the existing studies and thus their individual effect 
cannot be isolated $[17,23,24,62,63]$. In this study, the critical stress states obtained from the simulations can be plotted in the $q-p^{\prime}$ plane. As seen in Fig. 12, the critical stress ratio for samples with either spherical or clumped particles can be fitted by straight lines with different slopes, indicating that the critical state ratio is only affected by the particle shape via $O R$, but is independent of the PSD, initial density, stress path and drainage conditions. The critical stress ratio $M_{\mathrm{c}}=1.04$ and friction angle $\phi_{\mathrm{cs}}$ $=26.31^{\circ}$ for $O R=0.914$ are much greater than $M_{\mathrm{c}}=0.77$ and $\phi_{\mathrm{cs}}=19.95^{\circ}$ for $O R=1$. This observation is in agreement with previous DEM studies [11,37,64-66] and laboratory experiments $[15,19,67,68]$. In particular, as shown in [19], the critical friction angle $\phi_{\text {cs }}$ can be linearly correlated with the shape parameters such as roundness $R$ (roundness) or overall regularity $O R$. The shape parameter $O R$ is considered more appropriate as the roundness $R(=1)$ cannot distinguish the two types of particles employed in this study.

\section{Influence of particle shape and PSD on critical state line (CSL)}

Li and Wang [69] proposed an approach to linearize the critical state line (CSL) in the $e-\left(p^{\prime} / p_{a}\right)^{\xi}$ plane for sand, which can be expressed as:

$$
e_{c}=e_{\Gamma}-\lambda_{c}\left(p^{\prime} / p_{a}\right)^{\xi}
$$

where $p_{a}$ is the atmospheric pressure $(101.325 \mathrm{kPa})$ serving for normalization, $e_{\Gamma}$ is the intersection of CSL on the $e$-axis, $\lambda_{\mathrm{c}}$ is the slope of CSL, and $\xi$ is a constant parameter used for fine tuning. As noted by [52], $\xi$ is not a sensitive parameter and can be set to be 1.0 for simplicity in the present study.

Fig. 13 shows the critical state lines fitted by Eq. (7) from the samples composed with spheres $(O R=1)$, but with different PSDs. It is seen that unlike the critical stress ratio, the CSL depends on the grading of the particles. The parameters of CSL for each PSD are provided in Fig. 13 indicating that the multiple CSLs in the e-p' plane are approximately parallel, as the slope of CSLs only varies in a narrow range of $0.007 \sim 0.009$. The PSD only affects the intersection of CSL on the e-axis. Note that the specimens with non-disperse particles have a higher intercept which decreases as $C_{\mathrm{u}}$ increases. In the tests using two PSDs of natural Fujian sand by Yang and Luo [16], it was found that $C_{\mathrm{u}}$ has significant influence on the intercept of CSL on the $e$-axis, while moderate effects on the slopes of CSL were also observed. However, based on the numerical simulations involving three PSDs by Yan and Dong [37], it was suggested that both the changes in the intercept and slope of CSL due to grading should be addressed in constitutive models. The results of the present studies are broadly consistent with the conclusions in [16] and [37], especially the influence on the intercept of CSL which is rather intuitive. Note that the wider the PSD is, the denser the packing is. Thus, the intersection $e_{\Gamma}$, regarded as the void ratio at the extremely low p', should be smaller. However, whether the slopes of the multiple CSLs vary with $C_{\mathrm{u}}$ is still open for further investigation.

The similar downward shifting of CSLs for samples composed by clumped particles with varying PSDs is presented in Fig. 14, and is also confirmed by the experimental tests on silica sand by Russell and Khalili [70] and Ghafghazi et al [25]. However, the tests on carbonate sand by Bandini and Coop [24] indicated that the change of CSLs for samples with particle crushing (varying PSD) includes both translation and rotation in e- $p$ ' plane, which is also confirmed by Yang and Luo [19], who considered an even wider $C_{\mathrm{u}}$ range (1.2 3.56) on the mixture of natural silica sand and glass beads (both spherical and angular by artificial crushing). Although all the results suggest that the CSL may change due to the change in PSD, while the mode of position changes, i.e. translational offset or rotational shift, is still 
inconclusive.

Nevertheless, the two parameters $e_{\Gamma}$ and $\lambda_{\mathrm{c}}$ for the expression of the CSLs can be correlated with the grading parameter $C_{\mathrm{u}}$, as shown in Figs. 15a and 15b. Similar exponential expressions were proposed based on experiment tests from Biarez and Hicher [71]. It is seen in Fig. 15a that, a unique exponential relation of the slope $\lambda_{\mathrm{c}}$ decaying with $C_{\mathrm{u}}$ exists, irrespective of constituted particle shape in the samples. Similar exponential functions can be proposed for intersect $e_{\Gamma}$ falling with $C_{\mathrm{u}}$, but the expression of the function depends on the particle shape parameter $O R$, as illustrated in Fig. 15b.

\section{Influence of particle shape and PSD on critical state fabric}

Fig. 16 presents the critical values $F_{\mathrm{c}}$ ' of all simulations performed considering varying PSD and particle shape. Solid and hollow points represent the samples made up of clumped $(O R=0.914)$ and sphere $(O R=1)$ particles, respectively. Overall, the critical fabric norm $F_{\mathrm{c}}$ ' for the samples with $O R=0.914$ is greater than that for $O R=1$. Although the scatter exists for these two groups of data, there appears to have two distinct unique values of the critical fabric norm, which are independent of either critical void ratio $e_{\mathrm{c}}$ or mean stress $p^{\prime}$, as advocated by the ACST. The data shown in Fig. 16 leads to the mean $F_{c}^{\prime}=0.283$ for $O R=1$ and $F_{c}^{\prime}=0.511$ for $O R=0.914$. Coefficient of variation $(\mathrm{CoV})$ is used to quantify the degree of the fabric norm deviating from the mean value. Two unique trends by dashed lines are provided in Fig. 16, and the respective $F_{\mathrm{c}}{ }^{\prime}$ is given by its mean value. In general, the CoV for $O R=1$ is greater than $O R=0.914$, which is similar to that obtained by Xie et al. [11], possibly due to the same simple normalization rule used ( Eq. (5)), when tackling the adaption of DEM fabric tensor for samples involving spherical particles.

Recently, synchrotron X-ray micro-computed tomography was used to acquire 3D images during in-situ conventional triaxial compression experiments on four granular materials with different particle surface morphologies but having a uniform PSD [72]. It was found that under compression tests, the fabric, defined based on contact normal vectors, reached a steady fabric norm and its direction evolved to loading direction at critical state. This experimental data broadly supports the ACST, provided the samples had no shear banding prior to the arrival of the critical state. Note that the critical fabric norm varied from different sands, implying that $F_{c}^{\prime}$ was intimately related to the particle shape, as illustrated in the present study. Interestingly, the critical fabric norm seems not to be affected by the grading of the samples if the mean diameter $D_{50}$ is fixed. That is to say, $F_{c}^{\prime}$ might only depend on the particle shape under same loading mode.

\section{Conclusions}

This paper presents a systematic 3D DEM analysis of the effects of both the particle shape and PSD on the mechanical behavior of granular assemblies. A particular emphasis is placed on the critical state behavior interpreted within the framework of the anisotropic critical state theory (ACST). A series of triaxial tests under varying stress paths were performed, considering the combinations of the variations in the particle shape, PSD and initial density of the samples. Effects of both the particle shape and PSD on the stress strain response and volumetric characteristics have been discussed. The critical state behavior in both macroscopic and microscopic scales was also examined in terms of the critical stress ratio and CSL positions in e-p' space, as well as the fabric measures at critical state. Based on the simulation results, the following conclusions can be made: 
1. The numerical strategy employed in this study using DEM simulations allows for the isolation of the effects of the particle shape and particle-size distribution on the mechanical behavior of a granular assembly. In the numerical simulations, a synthetic shape parameter, termed overall regularity $(O R)$ is used to characterize the shape features of the different particles that composed the test samples. The grading of the samples can be distinguished by $C_{\mathrm{u}}$ but keeping other parameters of grading constant $\left(C_{\mathrm{c}}\right.$ and $\left.D_{50}\right)$.

2. It has been shown that both the PSD and $O R$ may affect the shearing responses of the samples significantly under three stress paths considered in this study. The samples with smaller $C_{\mathrm{u}}$ appear to be stiffer and more dilative than those with greater $C_{\mathrm{u}}$. This observation applies to both samples composed by spheres or clumped particles.

3. The critical state stress ratio is found to solely be related to the particle shape $O R$, irrespectively of the PSD. Overall, the samples made by the clumped particles have higher shear resistance at critical state than those by the spheres. The critical state line (CSL) is non-unique in the $e-p$ ' plane and influenced by both the particle shape and PSD. The multiple CSLs resulting from all the simulations indicate that the location of the CSL for the specimens with non-disperse particles is higher than for those with $C_{\mathrm{u}}>1$.

4. The microstructure evolution can be quantified with the deviatoric fabric tensor in terms of both its norm and direction. It is seen that apart from the critical state conditions required by the classical critical state theory, the critical state conditions associated with the microscopic features represented by the fabric tensor are also concurrently satisfied.

5. The critical fabric norm adapted by the normalization by specific volume appears to have a unique value for a given shear mode, while independent of the critical void ratio or mean stress. The apparent deviation of the data is considered to be due to the inaccurate normalization rule applied, which seems sensitive to the particle shape. Furthermore, although the unique critical fabric norm is only applicable to the same materials (characterized by the PSD), the samples with different $C_{\mathrm{u}}$ tend to have the same value of the critical state norm.

6. As $C_{\mathrm{u}}$ and $O R$ decrease, the critical state coordination number appears to increase. The coordination number is found to be stabilized at relatively small strain level $(<10 \%)$ but the fabric is still evolving towards the critical state. A steep drop in the coordination number may indicate the structure collapse of the specimen, e.g. liquefaction.

Real soil is seldom spherical or uniform. Even though samples with simple clumped particles can mimic more realistic soil behavior, such as higher shear strength than spherical particles, the shape parameter $O R$ of clumped particles (e.g. $O R=0.914$ in this study) is still higher than that of real sand particles, e.g. $O R \sim 0.86$ for Fujian sand [19], $O R \sim 0.68$ for Leighton Buzzard sand, $O R \sim 0.63$ for Toyoura sand, and $O R \sim 0.60$ for Ticino sand [73]. Moreover, simple clumped particles might be too idealized to capture some crucial features of sand mechanical behavior, such as convex-concave contact effects, which might affect the microstructural evolution and critical state response. Hence more realistic particle shapes need to be considered in DEM simulations and the corresponding response should be analyzed under the framework of ACST. More advanced techniques, such as spheropolygons and spheropolytopes methods proposed by Torres [74] can be applied to consider complex-shaped particles in the simulations. In addition, as the CSL location in the $e-p$ ' plane is found to be sensitive to the fines content, produced due to particle breakage $[23,72,75]$, more wider range of 
$C_{\mathrm{u}}$ of the PSD needs to be considered in DEM simulations in further investigation.

\section{Acknowledgments}

The research was funded by the National Key Research and Development Program of China (No.2016YFC0800200) and Natural Science Foundation of China (Grant Nos. 51578499 and 51761130078).

\section{Compliance with ethical standards.}

Conflict of interest: The authors declare that they have no conflict of interest.

\section{References}

1. Roscoe, K. H., Schofield, A. N., and Wroth, C. P.: On the yielding of soils. Géotechnique, 8(1), 22-53 (1958).

2. Schofield, A. N., and Wroth, P.: Critical state soil mechanics. 7(70), 23-56 (1968).

3. Li, X. S., and Dafalias, Y. F.: Anisotropic critical state theory: role of fabric. Journal of Engineering Mechanics, 138(3), 263-275 (2012).

4. Dafalias, Y. F., and Taiebat, M.: SANISAND-Z: zero elastic range sand plasticity model. Géotechnique, 66(12), 999-1013 (2016).

5. Chen, Y. N., and Yang, Z.X.: A family of improved yield surfaces and their application in modeling of isotropically over-consolidated clays. Computers and Geotechnics, 90, 133-143 (2017).

6. Yin, Z. Y., Wu, Z. X., Hicher, P. Y.: Modeling monotonic and cyclic behavior of granular materials by exponential constitutive function. Journal of Engineering Mechanics, 144(4): 04018014 (2018).

7. Yang, Z. X., Xu, T. T., Chen, Y. N.: J2-deformation type model coupled with state dependent dilatancy, Computers and Geotechnics, 105, 129-141 (2019).

8. Zhao, J., and Guo, N.: A new definition on critical state of granular media accounting for fabric anisotropy. 229-232 (2013).

9. Yang, Z. X., and Wu, Y.: Critical state for anisotropic granular materials: a discrete element perspective. International Journal of Geomechanics, 17(2), 04016054 (2017).

10. Li, X. S., and Dafalias, Y. F.: Dissipation consistent fabric tensor definition from DEM to continuum for granular media. Journal of the Mechanics and Physics of Solids, 78, 141-153 (2015)

11. Xie, Y. H., Yang, Z. X., Barreto, D., and Jiang, M. D.: The influence of particle geometry and the intermediate stress ratio on the shear behavior of granular materials. Granular Matter, 19(2), 35 (2017).

12. Thornton, C.: Thornton, C.: Numerical simulations of deviatoric shear deformation of granular media. Géotechnique 50(1), 43-53. Géotechnique, 50(1), 43-53 (2000).

13. Taylor, D. W.: Fundamentals of soil mechanics, John Wiley and Sons, (1948).

14. Santamarina, J. C.: Soil behaviour: the role of particle shape. Thomas Telford, (2004).

15. Cho, G. C., Dodds, J., and Santamarina, J. C.: Particle shape effects on packing density, stiffness, 
and strength: natural and crushed sands. Journal of Geotechnical and Geoenvironmental Engineering, 133(11), 591-602 (2006).

16. Yang, J., and Luo, X. D.: Exploring the relationship between critical state and particle shape for granular materials. Journal of the Mechanics and Physics of Solids, 84, 196-213 (2015).

17. Kokusho, T., Hara, T., and Hiraoka, R.: Undrained shear strength of granular soils with different particle gradations. Journal of Geotechnical and Geoenvironmental Engineering, 130(6), 621-629 (2004)

18. Simoni, A., and Houlsby, G. T.: The direct shear strength and dilatancy of sand-gravel mixtures. Geotechnical and Geological Engineering, 24(3), 523-549 (2006).

19. Yang, J., and Luo, X. D.: The critical state friction angle of granular materials: does it depend on grading? Acta Geotechnica, (2), 1-13 (2017).

20. Azéma, E., Linero, S., Estrada, N., and Lizcano, A.: Does modifying the particle size distribution of a granular material (i.e., material scalping) alters its shear strength? Powders and Grains 2017 proceedings. 140, 06001 (2017)

21. Wood, D. M., and Maeda, K.: Changing grading of soil: effect on critical states. Acta Geotechnica, 3(1), 3-14 (2008).

22. Muir, W. D.: Modelling mechanical consequences of erosion. Géotechnique, 60(6), 447-457 (2010).

23. Carrera, A., Coop, M., and Lancellotta, R.: Influence of grading on the mechanical behaviour of Stava tailings. Géotechnique, 61(11), 935-946 (2011).

24. Bandini, V., and Coop, M. R.: The influence of particle breakage on the location of the crticial state line of sands. South Atlantic Quarterly, 51(4), 591-600 (2011).

25. Ghafghazi, M., Shuttle, D. A., and Dejong, J. T.: Particle breakage and the critical state of sand. Soils and Foundations, 54(3), 451-461 (2014).

26. Xiao, Y., Liu, H., Ding, X., Chen, Y., Jiang, J., and Zhang, W.: Influence of particle breakage on critical state line of rockfill material. International Journal of Geomechanics, 16(1), 04015031 (2016).

27. Cundall, P. A., and Strack, O. D. L.: A discrete numerical model for granular assemblies. Géotechnique, 30(30), 331-336 (1979).

28. Williams, J. R., Hocking, G., and Mustoe, G. G. W.: Theoretical basis of the discrete element method. Numerical Method in Engineering, Theory and Applications. Proceedings of International Conference on Numerical Methods in Engineering, 897-906, Rotterdam:A. A.Balkema, (1985).

29. Thornton, C., and Antony, S. J.: Quasi-static shear deformation of a soft particle system. Powder Technology, 109(1-3), 179-191 (2000).

30. Combe, G. L., and Roux, J. L.: Discrete numerical simulation, quasistatic deformation and the origins of strain in granular materials. Third international symposium on deformation characteristics of geomaterials, Lyon, France (2003)

31. O’Sullivan, C.: Particulate discrete element modelling: a geomechanics perspective. Applied Geotechnics: Spon Press/Taylor and Francis, UK (2011).

32. Nouguier-Lehon, C., Cambou, B., and Vincens, E.: Influence of particle shape and angularity on the behaviour of granular materials: a numerical analysis. International Journal for Numerical and Analytical Methods in Geomechanics, 27(14), 1207-1226 (2010).

33. Alonso-Marroquín, F.: Role of anisotropy in the elastoplastic response of a polygonal packing. 
Physical Review E, 71(1), 051304 (2005).

34. Peña A A, Lizcano A, Alonso-Marroquin F, and Herrmann, H. J.: Biaxial test simulations using a packing of polygonal particles. International Journal for Numerical and Analytical Methods in Geomechanics, 32(2), 143-160 (2010).

35. Ng, T. T.: Fabric evolution of ellipsoidal arrays with different particle shapes. Journal of Engineering Mechanics, 127(10), 994-999 (2001).

36. Ng, T. T.: Behavior of ellipsoids of two sizes. Journal of Geotechnical and Geoenvironmental Engineering, 130(10), 1077-1083 (2004).

37. Yan, W. M., and Dong, J.: Effect of particle grading on the response of an idealized granular assemblage. International Journal of Geomechanics, 11(4), 276-285 (2011).

38. Azéma, E., Radjai, F., and Dubois, F.: Packings of irregular polyhedral particles: strength, structure, and effects of angularity. Physical Review E, 87(6), 062203 (2013).

39. Azéma, E., and Radjai, F.: Force chains and contact network topology in sheared packings of elongated particles. Physical Review E, 85(3), 031303 (2012).

40. Boton, M., Azéma, E., Estrada, N., Radjai, F., and Lizcano, A.: Quasistatic rheology and microstructural description of sheared granular materials composed of platy particles. Physical Review E, 87(3), 032206 (2013).

41. Voivret, C., Radjaï, F., Delenne, J. Y., and El Youssoufi, M. S.: Multiscale force networks in highly polydisperse granular media. Physical Review Letters, 102(17), 178001 (2009).

42. Estrada, N.: Effects of grain size distribution on the packing fraction and shear strength of frictionless disk packings. Physical Review E, 94(6), 062903 (2016).

43. Nguyen, D. H., Azéma, E., Sornay, P., and Radjai, F.: Effects of shape and size polydispersity on strength properties of granular materials. Physical Review E, 91(3), 032203 (2015).

44. Azéma, E., Linero, S., Estrada, N., and Lizcano, A.: Shear strength and microstructure of polydisperse packings: The effect of size span and shape of particle size distribution. Physical Review E, 96(2), 022902 (2017).

45. Miao, G., and Airey, D.: Breakage and ultimate states for a carbonate sand. Géotechnique, 63(14), 1221-1229 (2013).

46. Yu, F.: Particle breakage and the critical state of sands. Géotechnique, 68(8), 713-719 (2017).

47. Jensen, R. P., Bosscher, P. J., Plesha, M. E., and Edil, T. B.: DEM simulation of granular media-structure interface: effects of surface roughness and particle shape. International Journal for Numerical and Analytical Methods in Geomechanics, 23(6), 531-547 (2015).

48. Potticary, M., Zervos, A., and Harkness, J.: The effect of particle elongation on the strength of granular materials. 24th Conference on Computational Mechanics, United Kingdom, 239-242 (2016).

49. Wadell, H.: Volume, shape, and roundness of rock particles. Journal of Geology, 40(5), 443-451 (1932).

50. Kozicki, J., and Donzé, F. V.: A new open-source software developed for numerical simulations using discrete modeling methods. Computer Methods in Applied Mechanics and Engineering, 197(49-50), 4429-4443 (2008).

51. Yang, Z. X., Yang, J., and Wang, L. Z.: Micro-scale modeling of anisotropy effects on undrained behavior of granular soils. Granular Matter, 15(5), 557-572 (2013).

52. Li, X., Yu, H. S., and Li, X. S.: A virtual experiment technique on the elementary behaviour of granular materials with discrete element method. International Journal for Numerical and 
Analytical Methods in Geomechanics, 37(1), 75-96 (2013).

53. Gu, X., Huang, M., and Qian, J.: DEM investigation on the evolution of microstructure in granular soils under shearing. Granular Matter, 16(1), 91-106 (2014).

54. Kuhn, M. R., Renken, H. E., Mixsell, A. D., and Kramer, S. L.: Investigation of cyclic liquefaction with discrete element simulations. Journal of Geotechnical and Geoenvironmental Engineering, 140(12), 04014075 (2014).

55. Oda, M., and Nakayama, H.: Introduction of inherent anisotropy of soils in the yield function. Studies in Applied Mechanics, 20, 81-90 (1988).

56. Yang, Z. X., Xu, T. T., and Chen, Y. N.: Unified modeling of the influence of consolidation conditions on monotonic soil response considering fabric evolution. Journal of Engineering Mechanics, 144(8), 04018073 (2018).

57. Thornton, C., and Antony, S. J.: Quasi-Static Deformation of Particulate Media. Philosophical Transactions Mathematical Physical and Engineering Sciences, 356(1747), 2763-2782 (1998).

58. Oda, M.: Co-ordination number and its relation to shear strength of granular material. Soils and Foundations, 17(2), 29-42 (1977).

59. Ravishankar, B. V., Vinod, J. S., and Sitharam, T. G.: Post-liquefaction undrained monotonie behaviour of sands: Experiments and DEM simulations. Géotechnique, 59(9), 739-749 (2009).

60. Edwards, S. F.: The equations of stress in a granular material. Physica A Statistical Mechanics and Its Applications, 249(1), 226-231 (1998).

61. Fannin, R. J., Shuttle, D. A., and Rousé, P. C.: Influence of roundness on the void ratio and strength of uniform sand. Géotechnique, 58(58), 227-231 (2008).

62. Murthy, T. G., Loukidis, D., Carraro, J. A. H., Prezzi, M., and Salgado, R.: Undrained monotonic response of clean and silty sands. Géotechnique, 57(3), 273-288 (2007).

63. Li, G., Liu, Y. J., Dano, C., and Hicher, P. Y.: Grading-dependent behavior of granular materials: from discrete to continuous modeling. Journal of Engineering Mechanics, 141(6), 04014172 (2017).

64. Kuhn, M. R.: The critical state of granular media: convergence, stationarity and disorder. Géotechnique, 66(11), 1-8 (2016).

65. Zhou, W., Yang, L., Ma, G., Chang, X., Cheng, Y., and Li, D.: Macro-micro responses of crushable granular materials in simulated true triaxial tests. Granular Matter, 17(4), 497-509 (2015).

66. Thornton, C., and Zhang, L.: On the evolution of stress and microstructure during general 3D deviatoric straining of granular media. Géotechnique, 60(5), 333-341 (2010).

67. Sadrekarimi, A., and Olson, S. M.: Critical state friction angle of sands. Géotechnique, 61(9), 771-783 (2011).

68. O'Sullivan, C., Coop, M. R., and Cavarretta, I.: The influence of particle characteristics on the behavior of coarse grained soils. Géotechnique, 60(6), 413-423 (2010).

69. Li, X. S., and Wang, Y.: Linear representation of steady-state line for sand. Journal of Geotechnical and Geoenvironmental Engineering, 124(12), 1215-1217 (1998).

70. Russell, A. R., and Khalili, N.: A bounding surface plasticity model for sands exhibiting particle crus... Canadian Geotechnical Journal, 41(6), 1179-1192 (2004).

71. Biarez, J., and Hicher, P.: Influence de la granulométrie et de son évolution par ruptures de grains sur le comportement mécanique de matériaux granulaires. Revue Française De Génie Civil, 1(4), 607-631 (1997). 
72. Imseeh, W. H., Druckrey, A. M., and Alshibli, K. A.: 3D experimental quantification of fabric and fabric evolution of sheared granular materials using synchrotron micro-computed tomography. Granular Matter, 20(2), 24 (2018).

73. Cavarretta, I.: The influence of particle characteristics on the engineering behaviour of granular materials (Doctoral dissertation). Imperial College London, (2010).

74. Galindo-Torres, S. A., Muñoz, J. D., and Alonso-Marroquín, F.: Minkowski-Voronoi diagrams as a method to generate random packings of spheropolygons for the simulation of soils. Physical Review E, 82(5), 056713 (2010).

75. Thevanayagam, S., Shenthan, T., Mohan, S., and Liang, J.: Undrained fragility of clean sands, silty sands, and sandy silts. Journal of Geotechnical and Geoenvironmental Engineering, 128(10), 849-859 (2002).

Table 1 Parameters of particle shape

\begin{tabular}{c|c|c|c|c|c}
\hline Shape & $\begin{array}{c}\text { Aspect } \\
\text { Ratio }\end{array}$ & Roundness & Convexity & Sphericity & $\begin{array}{c}\text { Overall } \\
\text { Regularity }\end{array}$ \\
\hline & 1 & 1 & 1 & 1 & 1 \\
\hline & 0.714 & 1 & 0.978 & 0.964 & 0.914 \\
\hline
\end{tabular}

Table 2 Parameters of PSD

\begin{tabular}{c|c|c|c}
\hline PSD Type & $C_{\mathrm{u}}\left(\mathrm{D}_{60} / \mathrm{D}_{10}\right)$ & $C_{\mathrm{c}}\left(\mathrm{D}_{30}^{2} /\left(\mathrm{D}_{10} \mathrm{D}_{60}\right)\right)$ & $\mathrm{D}_{50}(\mathrm{~mm})$ \\
\hline PSD_1 & 1.000 & 1.000 & 0.26 \\
\hline PSD_2 & 1.435 & 0.998 & 0.26 \\
\hline PSD_3 & 1.914 & 1.002 & 0.26 \\
\hline PSD_4 & 2.564 & 1.007 & 0.26 \\
\hline
\end{tabular}

Table 3 Parameters used in simulations

\begin{tabular}{c|c|c|c|c|c|c}
\hline $\begin{array}{c}\text { Particle } \\
\text { density } \\
\left(10^{6} \mathrm{~kg} / \mathrm{m}^{3}\right)\end{array}$ & $\begin{array}{c}\text { Normal } \\
\text { stiffness } \\
K_{\mathrm{n}} / \mathrm{d}(\mathrm{MPa})\end{array}$ & $\begin{array}{c}\text { Tangential } \\
\text { stiffness } \\
K_{\mathrm{s}} / \mathrm{d}(\mathrm{MPa})\end{array}$ & $\begin{array}{c}\text { Damping } \\
\text { ratio }\end{array}$ & $\begin{array}{c}\text { Unbalanced } \\
\text { force ratio }\end{array}$ & $\begin{array}{c}\text { Number of } \\
\text { clumps }(\mathrm{N})\end{array}$ & $\begin{array}{c}\text { Strain rate } \\
\left(\mathrm{s}^{-1}\right)\end{array}$ \\
\hline 2.65 & 100 & 100 & 0.2 & 0.0001 & 5000 & 0.05 \\
\hline
\end{tabular}




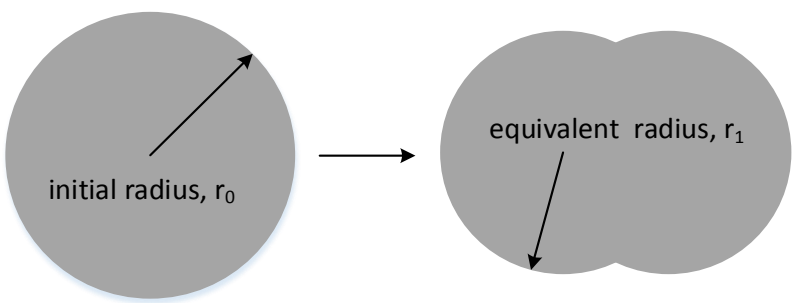

Fig. 1 Illustration of clumps and the equivalent diameter 
(a)

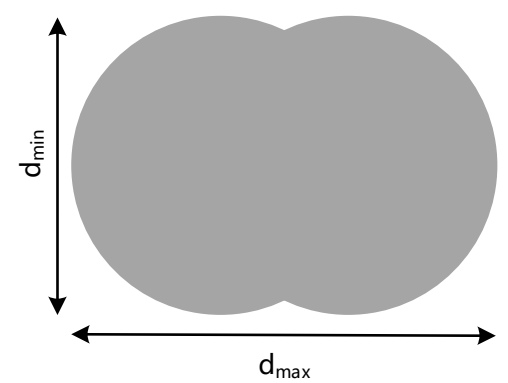

Aspect Ratio, $A R=d_{\min } / d_{\max }$

(c)

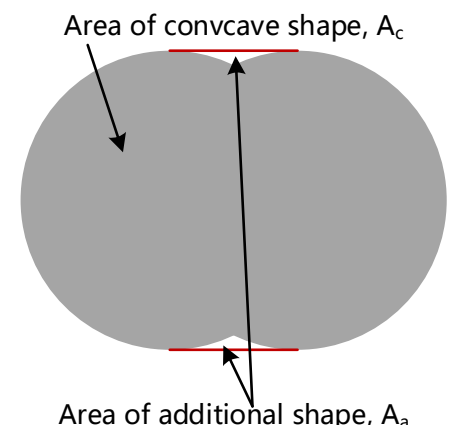

Convexity, $C=A_{c} /\left(A_{c}+A_{a}\right)$ (b)

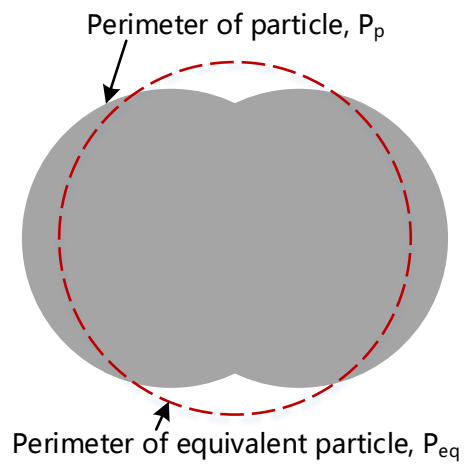

Sphericity, $S=P_{p} / P_{\text {eq }}$

(d)

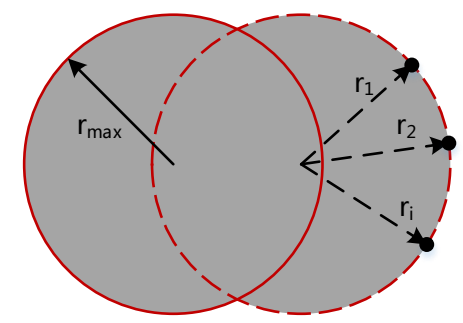

Roundness, $R=\Sigma r_{i} / N / r_{\max }$

Fig. 2 Illustration of particle shape measurements: (a) Aspect Ratio; (b) Sphericity; (c) Convexity; (d) Roundness 


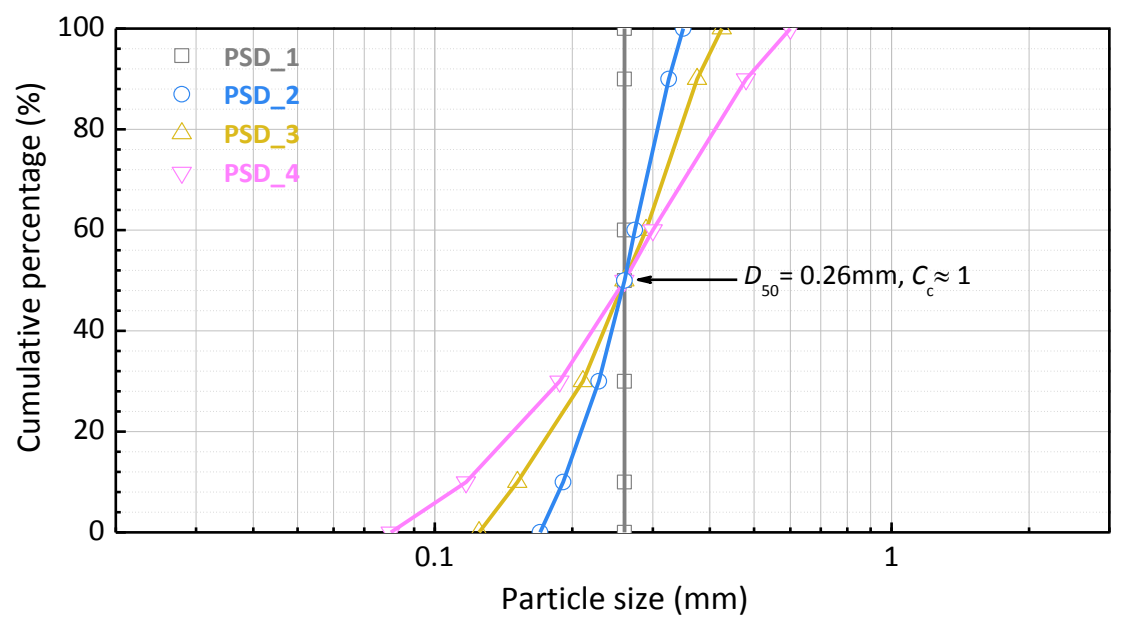

Fig. 3 Particle size distribution of assemblages 

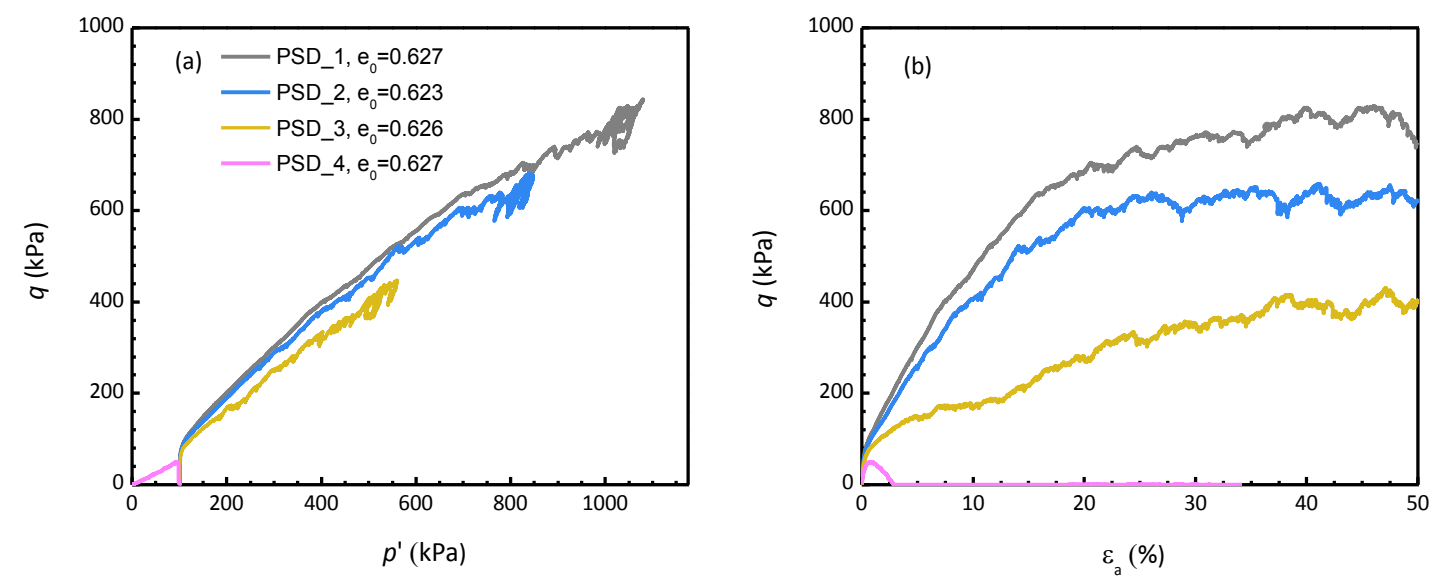

Fig. 4 Effects of PSD on constant volume shear behavior of samples with spherical particles $(O R=1)$ at $p_{0}{ }^{\prime}=100 \mathrm{kPa}$ : (a) effective stress paths; (b) deviatoric stress - axial strain curves 

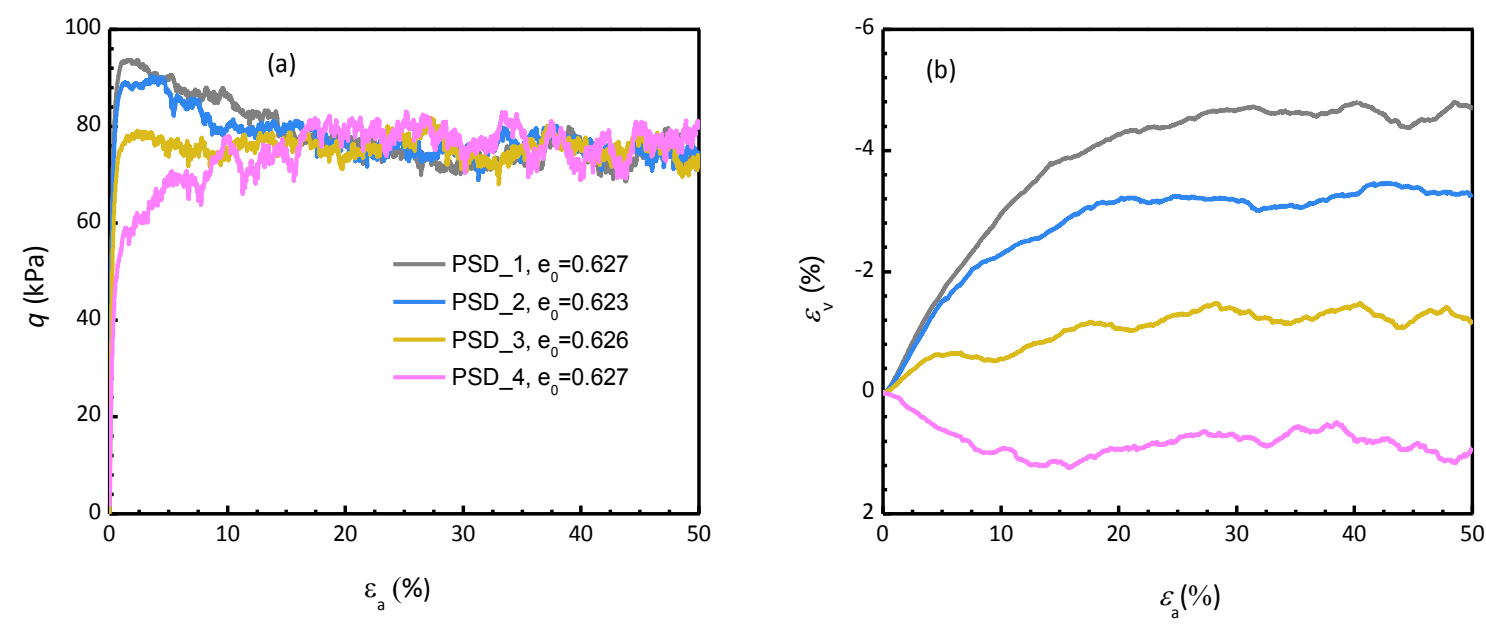

Fig. 5 Effects of PSD on constant $p^{\prime}$ drained shear behavior of samples with spherical particles $(O R=1)$ at $p_{0}^{\prime}=100 \mathrm{kPa}$ : (a) deviatoric stress - axial strain curves; (b) volumetric strain- axial strain relations 

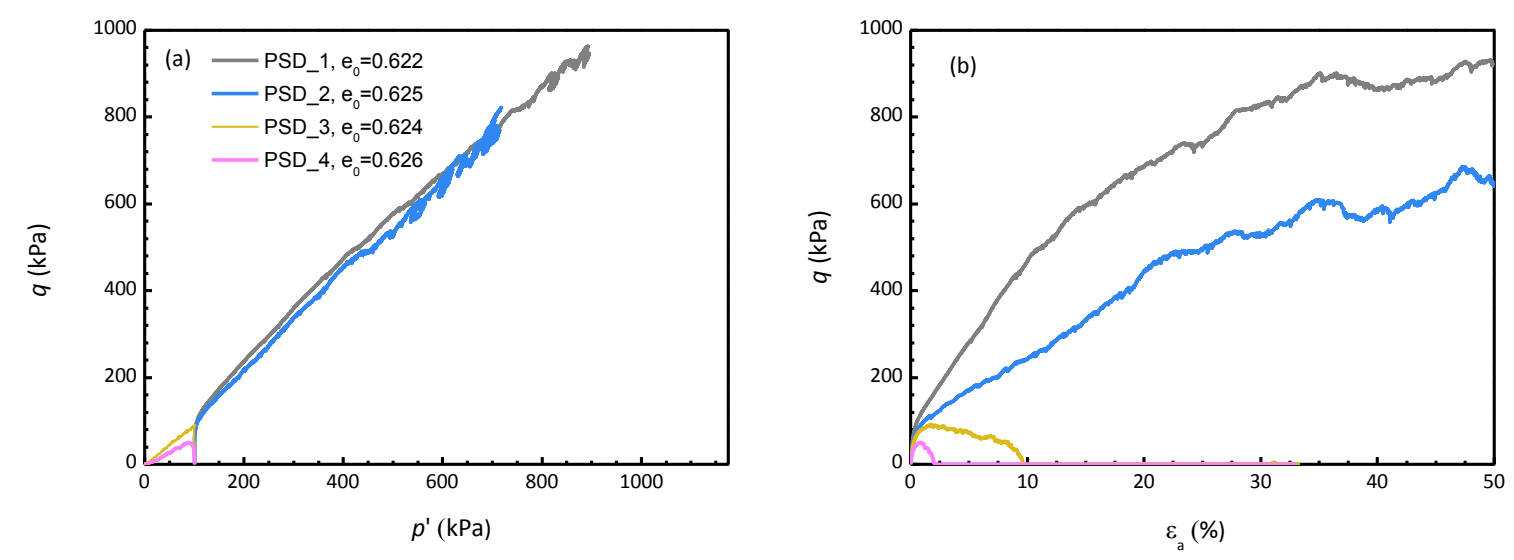

Fig. 6 Effects of PSD on constant volume shear behavior of samples with clumped particles $(O R=0.914)$ at $p_{0}{ }^{\prime}=100 \mathrm{kPa}$ ( (a) effective stress paths; (b) deviatoric stress - axial strain curves 

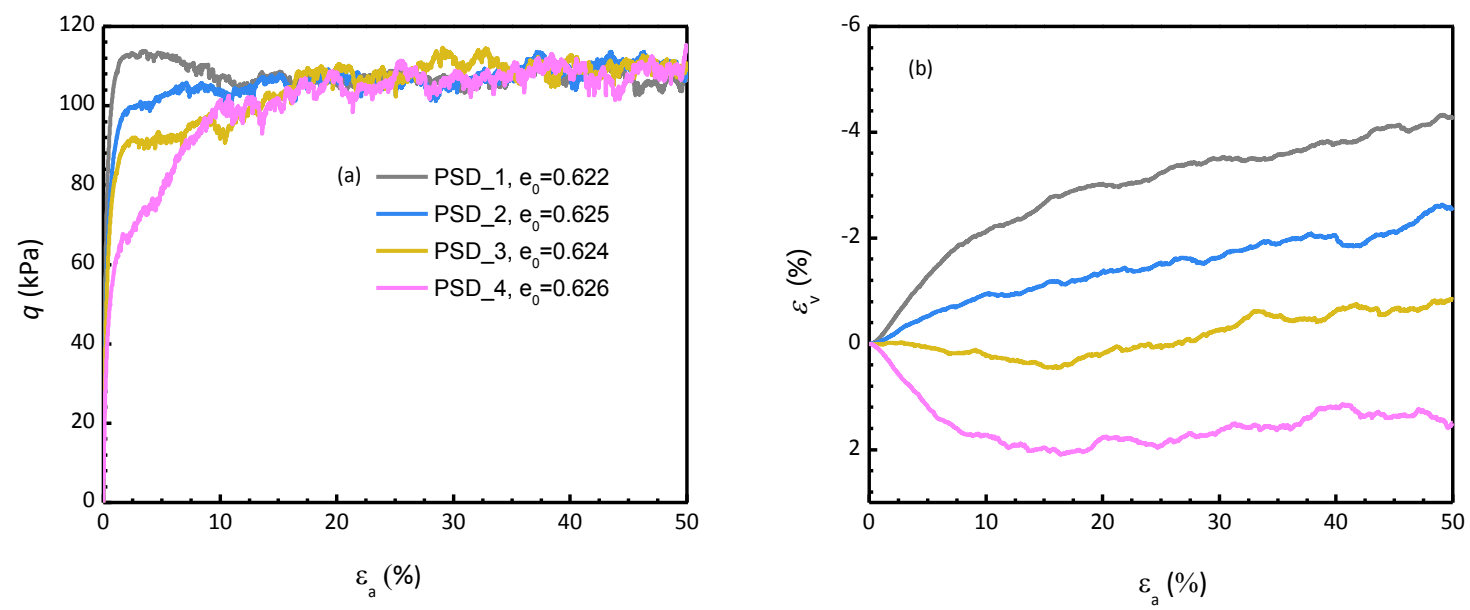

Fig. 7 Effects of PSD on constant p' shear behavior of samples with clumped particles (OR=0.914) at $p_{0}{ }^{\prime}=100 \mathrm{kPa}$ : (a) deviatoric stress - axial strain curves; (b) volumetric strain- axial strain relations 

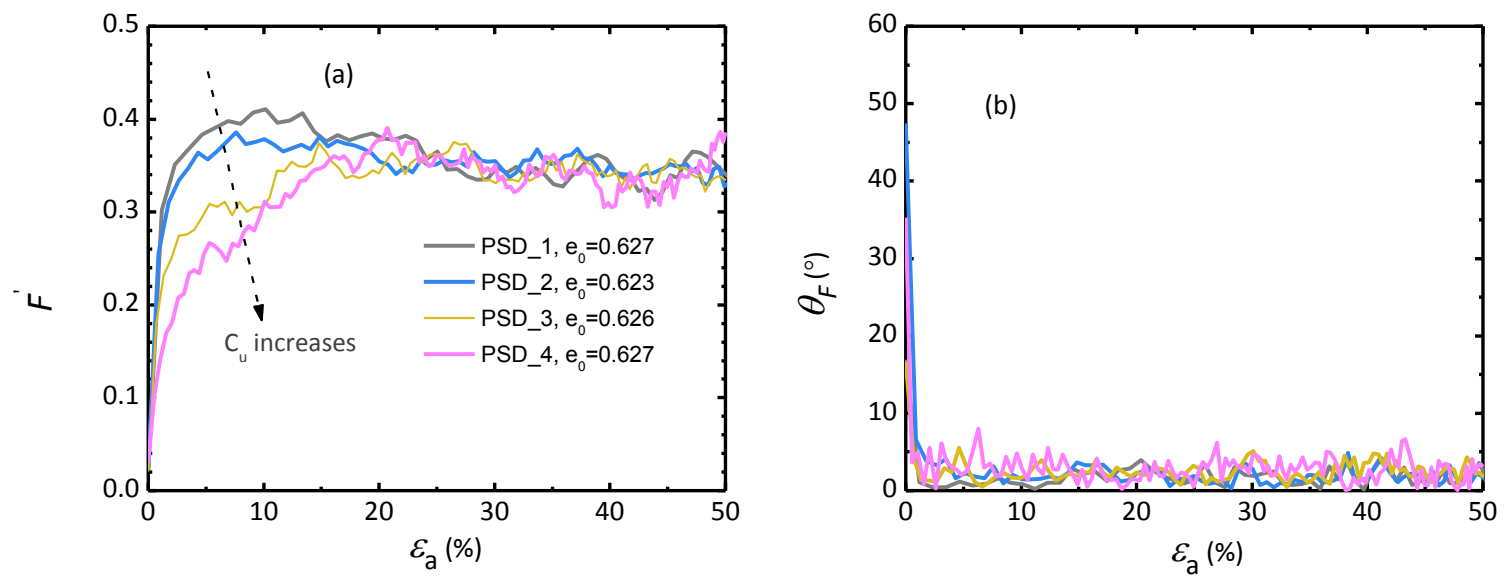

Fig. 8 Effects of PSD on the fabric evolution of samples with spherical particles (OR=1) under constant $p^{\prime}$ test at $p_{0}{ }^{\prime}=100 \mathrm{kPa}$ : (a) fabric norm $F^{\prime}$; (b) fabric Lode angle $\theta_{F}$ 

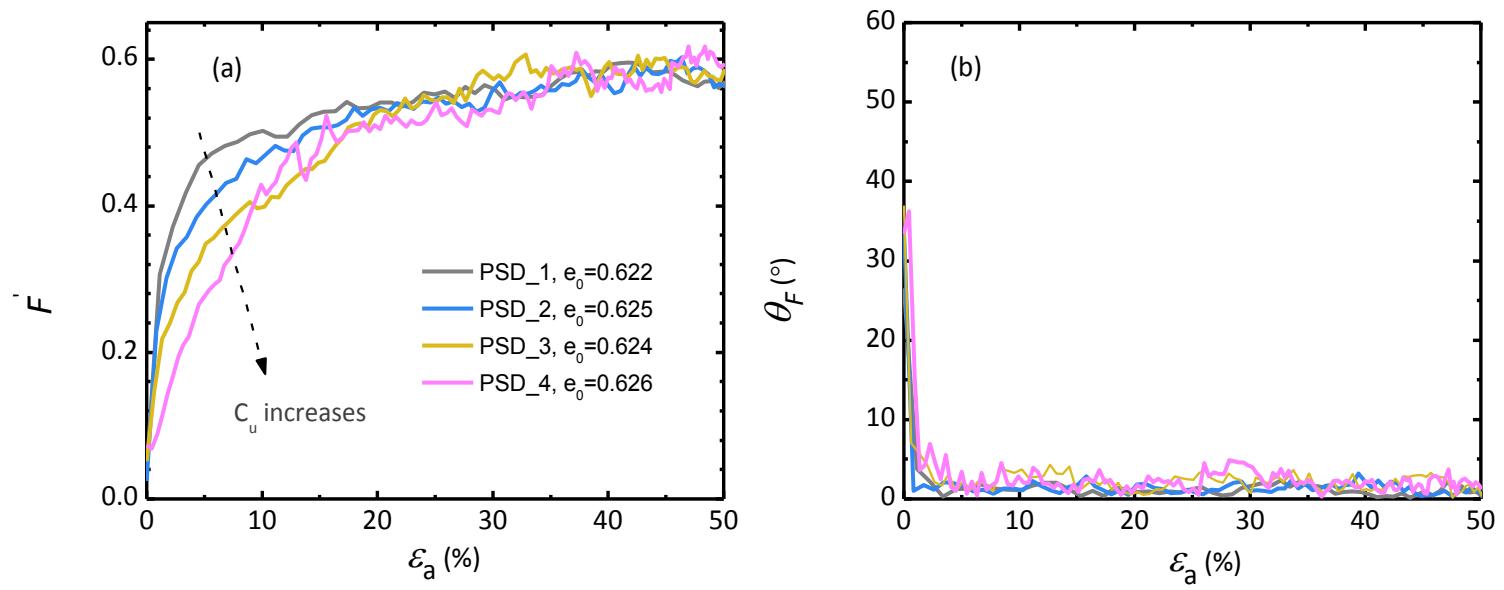

Fig. 9 Effects of PSD on the fabric evolution of samples with clumped particles $(O R=0.914)$ under constant $p^{\prime}$ test at $p_{0}{ }^{\prime}=100 \mathrm{kPa}$ : (a) fabric norm $F^{\prime}$; (b) fabric Lode angle $\theta_{F}$ 

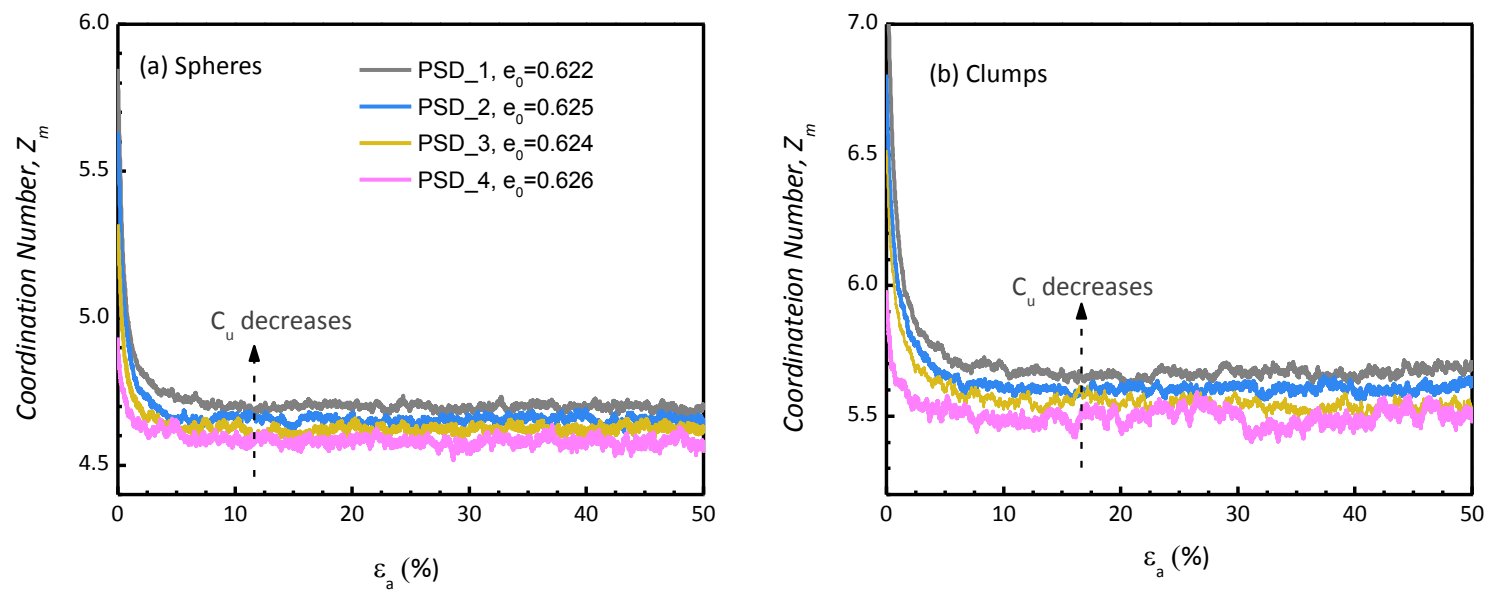

Fig. 10 Effects of PSD on the coordinate number under constant $p^{\prime}$ test at $p_{0}{ }^{\prime}=100 \mathrm{kPa}$ : (a) spherical particles $(O R=1)$; (b) clumped particles $(O R=0.914)$ 

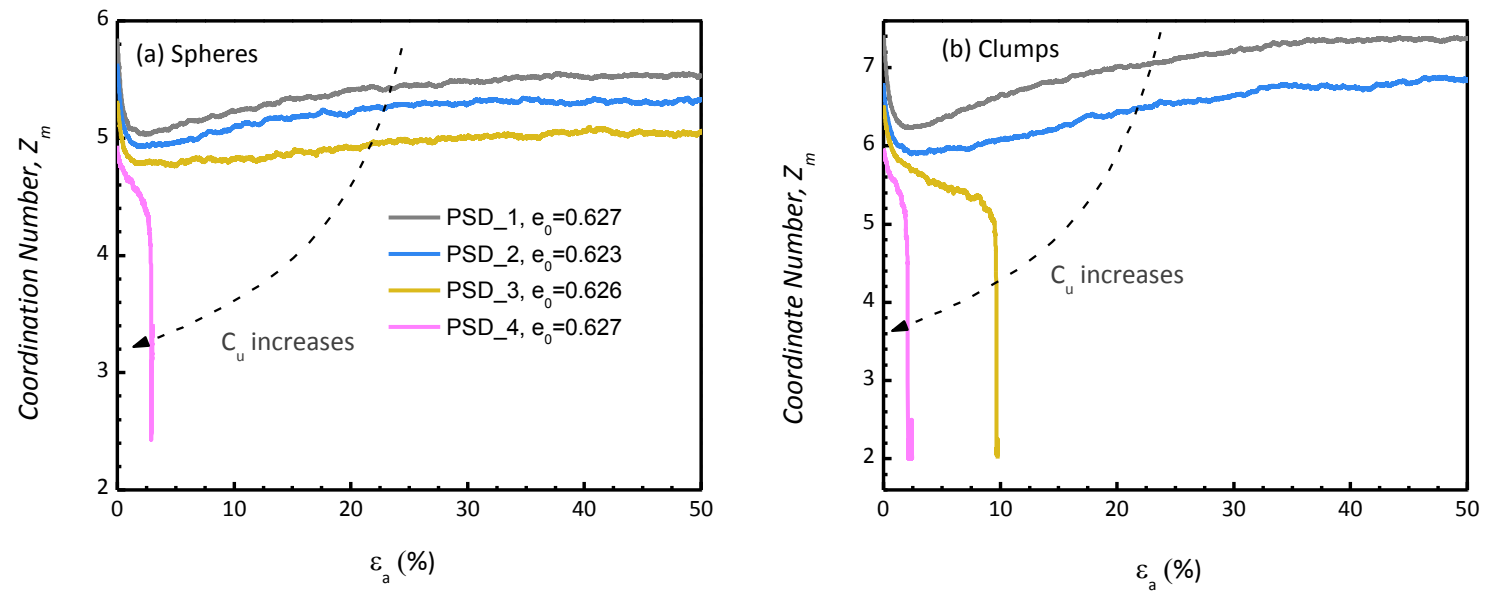

Fig. 11 Effects of PSD on the coordinate number under constant volume test at $p_{0}{ }^{\prime}=100 \mathrm{kPa}$ : (a) spherical particles $(O R=1)$; (b) clumped particles $(O R=0.914)$ 


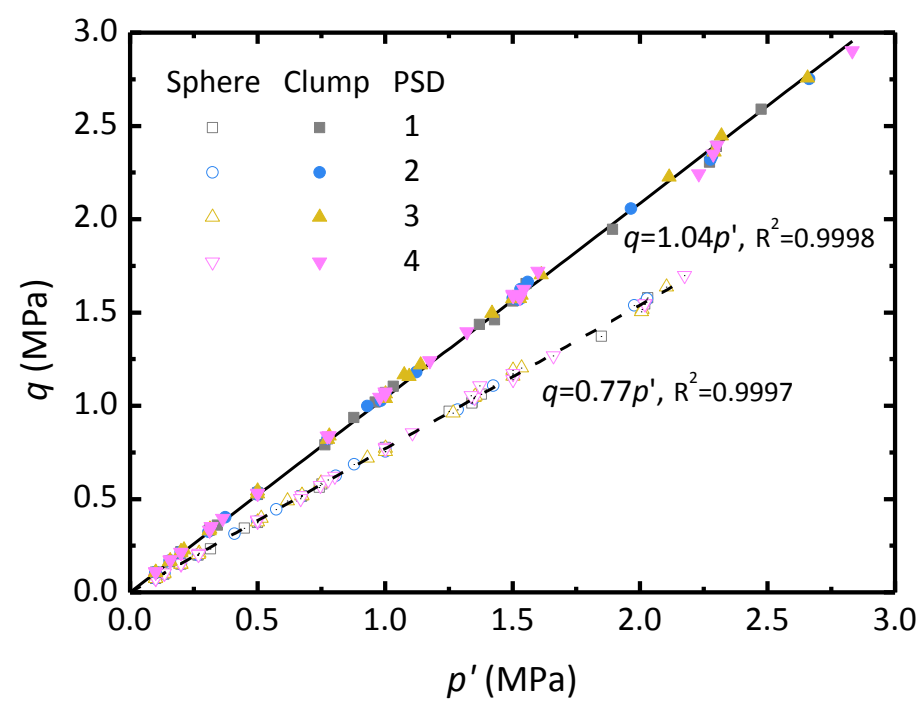

Fig. 12 Critical states in $p^{\prime}-q$ space for all the tested samples 


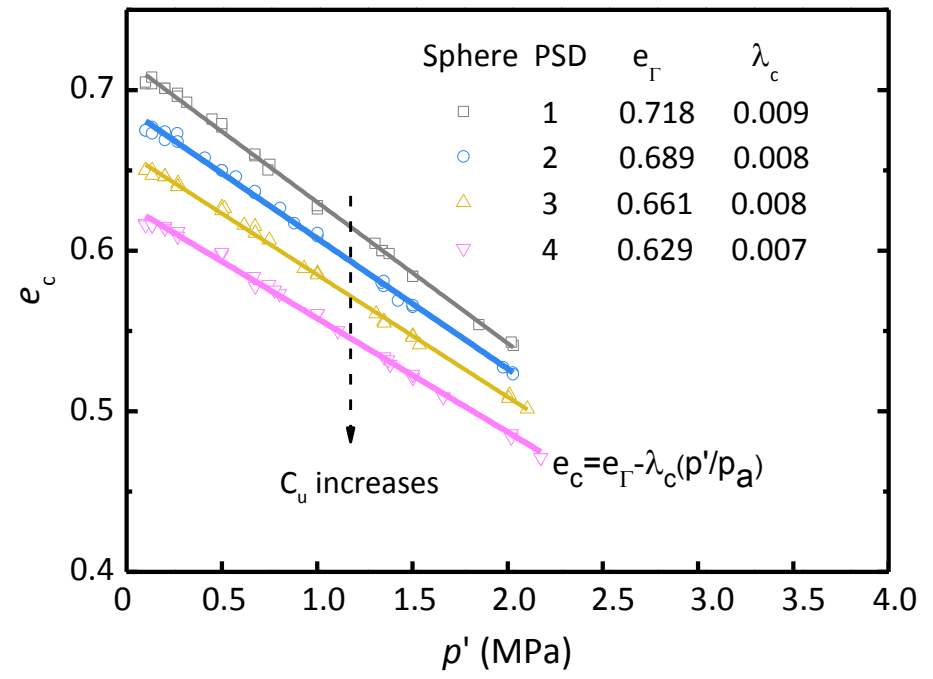

Fig. 13 Critical states in $e-p^{\prime}$ space of tested samples with spherical particles 


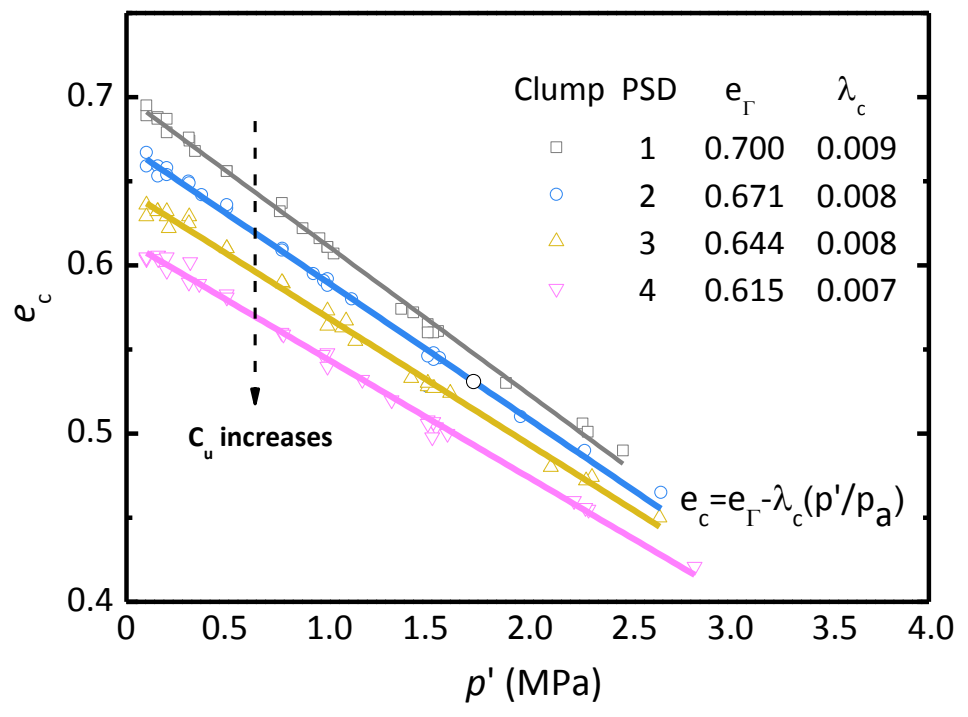

Fig. 14 Critical states in $e-p^{\prime}$ space of tested samples with clumped particles 

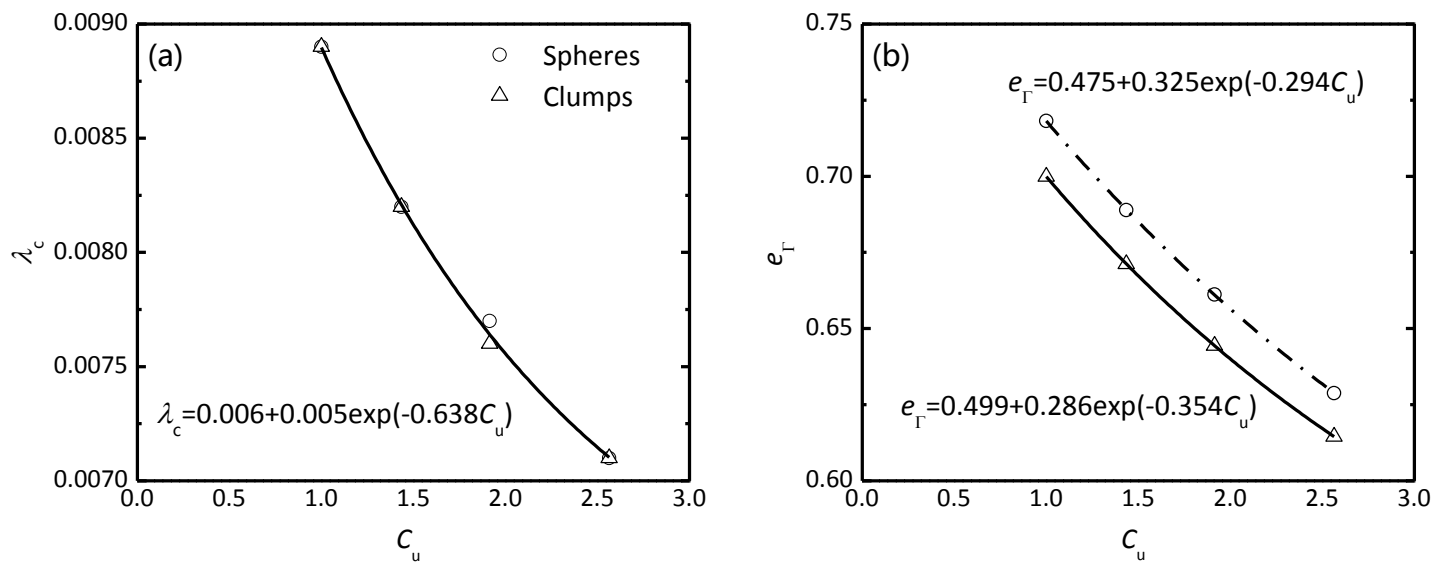

Fig. 15 Relationship between CSL parameters and $C_{\mathrm{u}}$ : (a) $\lambda_{\mathrm{c}}$ vs. $C_{\mathrm{u}}$; (b) $e_{\Gamma}$ vs. $C_{\mathrm{u}}$ 


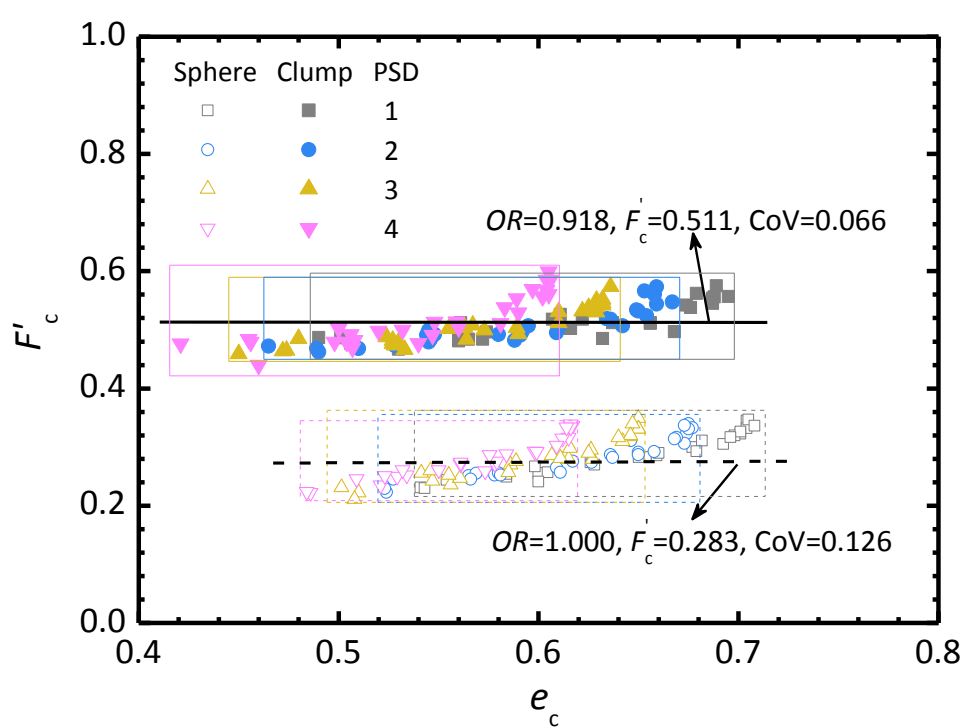

Fig. 16 Fabric norm - void ratio relationship at critical state of all compression tests 